\title{
Growth of Three Established Cell Lines on Glass Microcarriers
}

\author{
JAMES VARANI,* MICHAEL DAME, TED F. BEALS, and \\ JOHN A. WASS, Department of Pathology, The University of Michigan \\ Medical School, Ann Arbor, Michigan 48109
}

\begin{abstract}
Summary
Three established cell lines were examined for growth on a newly developed microcarrier which consists of glass beads. The cells were simultaneously examined for growth on commercially available microcarriers made from DEAE-dextran and from plastic. Cell yields on the glass microcarriers were comparable to the cell yields on the commercially available products. Cells grown on the glass microcarriers were easily separated from the substratum by trypsinization (as were the cells grown on the plastic substratum) while the cells grown on the DEAEdextran particles were much more trypsin resistant. After removal of cells from the glass microcarriers, the cells reattached and spread out in plastic flasks as readily as cells harvested from monolayer. Scanning electron microscopy revealed dramatic differences in the appearance of the cells grown on the glass microcarriers and cells grown on the DEAE-dextran microcarriers. On the glass microcarriers, cells attached to the substratum through long, slender filopodia while on the DEAE-dextran microcarriers, the entire edge of the cell appeared to be in contact with the substratum. This dissimilarity in attachment could underly the difference in sensitivity to trypsin-mediated detachment. Finally, the glass microcarriers were washed after being used once and retested for their ability to support cell growth a second time. Nearly identical results were obtained with the reprocessed beads as with previously unused ones.
\end{abstract}

\section{INTRODUCTION}

Since the introduction of microcarrier technology for the large-scale cultivation of anchorage-dependent cells more than a decade ago by van Wezel, ${ }^{1}$ a number of products have been successfully used as microcarriers. These include dextran particles substituted with positively charged $N, N$-diethylaminoethyl groups (DEAE-dextran) ${ }^{2}$ or with positively charged $N, N, N$-trimethyl-2-hydroxyaminopropyl groups, ${ }^{3}$ dextran particles coated with denatured collagen, ${ }^{3}$ polystyrene plastic, ${ }^{4}$ polyacrylamide ${ }^{5}$ and porous silica. ${ }^{5}$ Glass spheres (2-3 mm diameter) have been used in culture to extend the surface area.$^{6-8}$ Glass has not, however, been used in a true microcarrier system owing to the fact that its high density requires stirring speeds that are not compatible with cell growth. ${ }^{5,9}$ Except for the high density, glass spheres would likely make an ideal microcarrier since many cell types grow to high density in

*To whom all correspondence be addressed. 
monolayer cultures on glass. In this report we describe the growth of three established cell lines on a newly developed glass microcarrier with near-ideal density.

\section{MATERIALS AND METHODS}

\section{Microcarriers}

The experimental microcarriers used in this study are glass beads. They have a diameter range of $100-150 \mu \mathrm{m}$ and a particle density of $1.04 \mathrm{~g} / \mathrm{mL}$. There are approximately $5 \times 10^{5}$ beads $/ \mathrm{g}$ with a surface area of $385 \mathrm{~cm}^{2} / \mathrm{g}$. The glass beads are manufactured by KMS Fusion, Inc. (Ann Arbor, MI). Three commercially available microcarriers were used for comparative purposes in this study. These include Cytodex I (Pharmacia; Piscataway, NJ), Superbeads (Flow laboratories; McLean, VA) and Biosilon (A/S Nunc; Roskilde, Denmark).

\section{Cells}

Three human cell lines were used in this study. These include a line of human diploid fibroblasts (MRC-5), a cell line derived from a nasopharyngeal carcinoma (KB), and a line recently derived from a squamous cell carcinoma of the right mandibular alveolus (UM-SCC-2). The KB and MRC- 5 cells were obtained commercially from Flow Laboratories. The UM-SCC-2 cell line was established by Dr. Thomas Carey (Dept. of Otorhinolaryngology; The University of Michigan) and provided by him. ${ }^{10}$ Growth medium for the KB cells consisted of Minimal Essential Medium (MEM) of Eagle supplemented with $10 \%$ fetal bovine serum, $100 \mathrm{U} / \mathrm{mL}$ of penicillin, $100 \mu \mathrm{g} / \mathrm{mL}$ of streptomycin, and $2.5 \mu \mathrm{g} / \mathrm{ml}$ of fungizone. The RPMI-1640 medium supplemented with $10 \%$ fetal bovine serum and antibiotics was used with the MRC- 5 cells and the UMSCC- 2 cells. The medium and antibiotics were obtained from GIBCO (Grand Island, NY) and the serum was obtained from Kansas City Biological Co. (Lenexa, KS). The three cell types were routinely maintained in monolayer culture on plastic flasks (Costar $75 \mathrm{~cm}^{2}$ flasks; No. 3275; Cambridge, MA). The cells were grown at $37^{\circ} \mathrm{C}$ in medium equilibrated with $5 \% \mathrm{CO}_{2} / 95 \%$ air and subcultured by trypsinization as required. Prior to use, the lines were tested for mycoplasma contamination by growth on mycoplasma agar and in mycoplasma broth and found to be free of contamination. The mycoplasma testing was carried out by the University of Michigan Hospital Clinical Microbiology Laboratory. Stock cultures of each line were maintained in liquid nitrogen.

\section{Microcarriers Cultures}

Small scale $(2.5 \mathrm{~mL})$ microcarrier cultures were established with the three cell lines. Plastic petri plates ( $35 \mathrm{~mm}$; Falcon, No. 1008; Oxnard, CA) were used for these cultures. The glass microcarriers were tested at three different 
concentrations. These were $7.5,37.5$, and $75 \mathrm{mg} /$ plate. Quadruplicate cultures were established with each concentration. Tests with the three commercially available microcarriers were carried out using a single concentration of each type. The concentrations used were those recommended by the respective manufacturers. For Cytodex I and Superbeads, this was $7.5 \mathrm{mg} /$ plate; for Biosilon this was $60 \mathrm{mg} /$ plate. In addition to the microcarrier cultures, cells were also grown in monolayer culture. For this, tissue culture plates $(35 \mathrm{~mm}$; Costar, No. 3035) were used. A comparison of surface areas for the seven conditions employed is shown in Table 1.

In addition to the small-scale cultures, the KB cells were also grown on the glass microcarriers and on Cytodex I in larger volumes $(200 \mathrm{~mL})$. For the largescale cultures, a Techne (model MCS-104) stirring system was employed. Cytodex I at $600 \mathrm{mg} / \mathrm{flask}$ and glass microcarriers at $2000 \mathrm{mg} / \mathrm{flask}$ were used.

\section{Scanning Electron Microscopy}

The cells on the microcarriers were fixed for scanning electron microscopy by mixing an equal volume of $4 \%$ Sorenson's buffered glutaraldehyde with the culture fluid containing the microcarriers in suspension. After six hours, the microcarriers (and their attached cells) were decanted into glass vials. Post fixation in $1 \%$ osmium tetroxide buffered in $s$-collidine was followed by en bloc staining with uranyl acetate. Dehydration was in a graded series of ethanol. During the $70 \%$ ethanol step, the specimens were transferred to specially designed cylinders with screens at each end to allow free exchange of fluids but retain the spheres. Critical point drying was from absolute ethanol through liquid carbon dioxide. The spheres were mounted on stubs with double sticky tape and conductive coated with gold in a dc sputter coater. Following this, the

TABLE I

Small-Scale Culture Conditions

\begin{tabular}{lcc}
\hline \multicolumn{1}{c}{ Substratum } & $\begin{array}{c}\text { Microcarrier } \\
\text { Concentration } \\
(\mathrm{mg} / \mathrm{plate})\end{array}$ & $\begin{array}{c}\text { Surface area } \\
\left(\mathrm{cm}^{2} / \mathrm{plate}^{\mathrm{b}}\right)\end{array}$ \\
\hline The 35-mm (diameter) & - & 9 \\
$\quad$ tissue culture dish & 7.5 & 45 \\
Cytodex I & 7.5 & 36 \\
Superbead & 60 & 15 \\
Biosilon & 7.5 & 3 \\
Glass & 37.5 & 15 \\
Glass & 75 & 30 \\
Glass & 75 & \\
\hline
\end{tabular}

\footnotetext{
${ }^{a}$ The concentrations of the commercially available microcarriers were chosen based on the manufacturer's recommendations.

bSurface area of the microcarrier cultures does not include the surface area of the culture dishes.
} 
specimens were examined using an ISI Super IIIA scanning electron microscope.

\section{RESULTS}

\section{Quantitative Aspects}

Growth of the three cell lines on the glass microcarriers in small-scale cultures is shown in Figures 1-3. Cell growth in monolayer culture and on the commercially-available microcarriers is shown in the same figures. In all three figures, the open symbols (circles, squares, and triangles) represent the three concentrations of the experimental glass microcarriers. It can be seen in all three figures that cell growth on the experimental microcarriers is very similar to growth on the commercially available products. At the highest concentration of glass microcarriers $(75 \mathrm{mg} /$ plate), cell yields were actually slightly higher than on the other substrates. This is in spite of the fact that the total surface area was somewhat lower with the glass microcarriers than with the Cytodex I or Superbead microcarriers $\left(30 \mathrm{~cm}^{2} /\right.$ plate versus 45 and 36

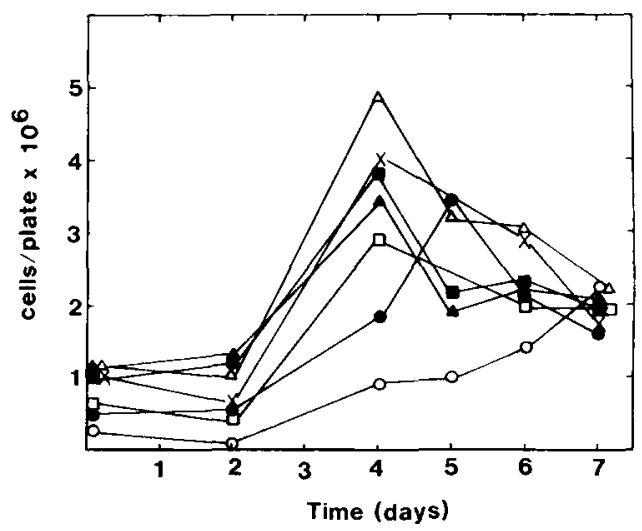

Fig. 1. Growth of KB cells in monolayer and on the various microcarriers. Each culture consisted of a 35-mm-diameter plate containing $2.5 \mathrm{~mL}$ of growth medium (MEM supplemented with $10 \%$ fetal bovine serum) and the appropriate amount of microcarriers. Tissue culture dishes (Costar No. 3035) were used for the monolayer cultures and plastic petri dishes (Falcon No. 1008) were used with the microcarriers. The cultures were established in quadruplicate on day zero. Starting on day two and on each day thereafter, the culture medium was replaced with fresh growth medium. In addition, the cells/microcarriers in each plate were gently aspirated with a pipette. This was done to break up the clumps of microcarriers which tended to form when cells were attached to them at high density. At each of the time periods indicated, duplicate samples from one or two plates were harvested and counted. Standard deviations were routinely within $10-15 \%$ of the mean values. The experiment was run twice and the values shown are the average of the two experiments combined: $(\bullet-\bullet)$ monolayer; ( $\square-\square)$ Cytodex I; (^-^) Superbeads; $(x-x)$ Biosilon; $(0-0)$ glass microcarriers at $3 \mathrm{~cm}^{2} /$ plate; ( $\left.\square-\square\right)$ glass microcarriers at $15 \mathrm{~cm}^{2} /$ plate, $(\Delta-\Delta)$ glass microcarriers at $30 \mathrm{~cm}^{2} /$ plates. 


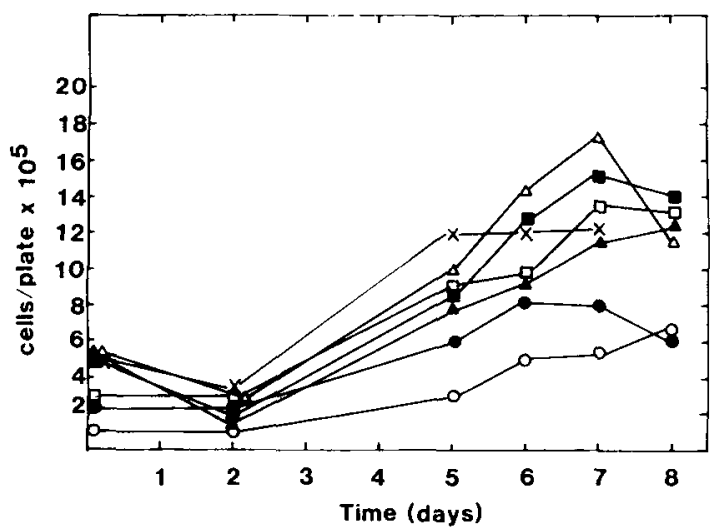

Fig. 2. Growth of MRC-5 cells in monolayer and on the various microcarriers. The experiment was carried out as described in the legend to Figure 1 except that RPMI-1640 was used as the growth medium. The experiment was run twice and the values shown are the averages of the

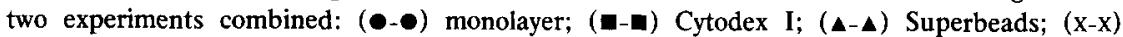
Biosilon; (0-0) glass microcarriers at $3 \mathrm{~cm}^{2} /$ plate; ( $\left.\square-\square\right)$ glass microcarriers at $15 \mathrm{~cm}^{2} /$ plate; $(\Delta-\Delta)$ glass microcarriers at $30 \mathrm{~cm}^{2} /$ plate.

$\mathrm{cm}^{2} /$ plate, respectively). Only at the lowest concentration of glass microcarriers ( $7.5 \mathrm{mg} / \mathrm{plate})$ were the cells yields significantly lower.

The enumeration of cell growth on each of the substrata was done following separation of the cells from the microcarriers or from the plastic culture dishes by trypsinization. During the course of this work it became obvious that the susceptibility of the cells to trypsin-mediated release from the microcarriers

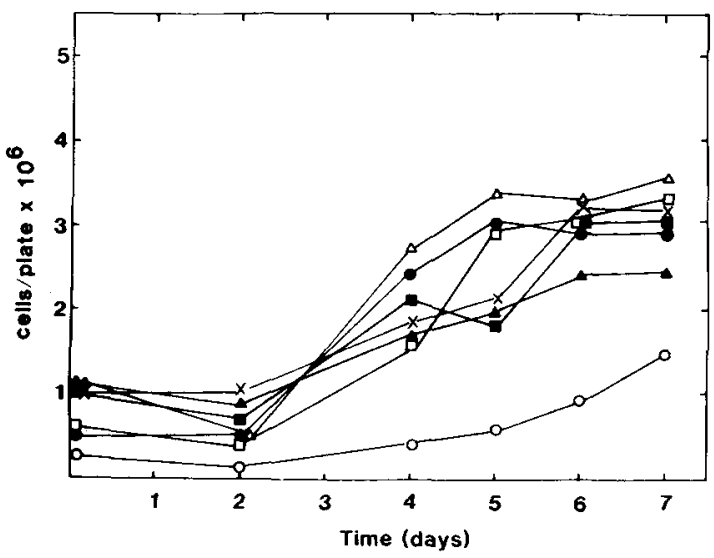

Fig. 3. Growth of UM-SCC-2 cells in monolayer and on the various microcarriers. The experiment was carried out as described in the legend to Figure 1 except that RPMI-1640 was used as the growth medium. The experiment was run twice and the values shown are the averages of

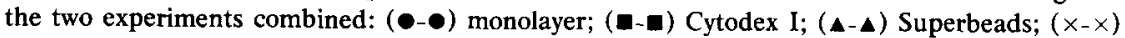
Biosilon; (O-O) glass microcarriers at $3 \mathrm{~cm}^{2} /$ plate; ( $\left.\square-\square\right)$ glass microcarriers at $15 \mathrm{~cm}^{2} /$ plate, $(\Delta-\Delta)$ glass microcarriers at $30 \mathrm{~cm}^{2} /$ plate. 
was a function of the substratum type. When grown on the plastic plates or on the glass or plastic microcarriers, 10-min trypsinization periods were all that were necessary to release the cells. In contrast, it was necessary to treat the cells grown on the DEAE-dextran polymers for up to $45 \mathrm{~min}$ with the same amount of trypsin in order to release the cells. Even after this prolonged period of incubation, it was necessary to vortex the suspension of microcarriers to separate the cells. Differences in susceptibility to trypsin-mediated release were found with all three cell types.

With each of the cell types, the samples for cell counting were obtained and handled in a sterile manner. After counting, the cells were washed and replated in tissue culture flasks on growth medium. Twenty-four hours later the cells in these flasks were examined microscopically. We found with all three of the cell types that cells harvested from the glass microcarriers reattached and spread as readily as did the cells harvested from the plastic plates. In contrast, many of the cells harvested from the DEAE-dextran microcarriers failed to spread when reincubated on the plastic flasks. This was possibly due to the fact that the cells grown on these microcarriers had to be treated much more vigorously in order to release them from the substratum.

Although the glass microcarriers proved to be a suitable substratum for the cultivation of ceils in small-scale stationary cultures, experiments with larger volumes were needed to determine whether cell growth in suspension could be maintained. To establish large-scale cultures, we used the Techne, Model MCS-104 Stirring System. The culture vessels consisted of 1000-mL flasks containing $200 \mathrm{~mL}$ of growth medium and either $2000 \mathrm{mg}$ of the glass microcarriers or $600 \mathrm{mg}$ of Cytodex I. The cultures were established on day zero and maintained as described in the Materials and Methods section. The results are shown in Figure 4. It can be seen that the cells grew well on the glass microcarriers when maintained in suspension by continuous stirring. The maximum cell yield was approximately $2.7 \times 10^{8}$ cells in the flask containing the glass microcarriers $\left(1.3 \times 10^{6}\right.$ cells $\left./ \mathrm{mL}\right)$. When the cell yield per $\mathrm{cm}^{2}$ of surface area was calculated, the yield from the suspension culture compared favorably with the cell yields in the small-scale stationary cultures. We obtained a yield of $4.5 \times 10^{5}$ cells $/ \mathrm{cm}^{2}$ of microcarrier surface area in the suspension culture as compared to $1.6 \times 10^{5}$ and $1.9 \times 10^{5}$ cells $/ \mathrm{cm}^{2}$ of surface area in the smallscale cultures containing $75 \mathrm{mg} /$ plate $\left(30 \mathrm{~cm}^{2} /\right.$ plate $)$ and $37.5 \mathrm{mg} /$ plate $(15$ $\mathrm{cm}^{2} /$ plate) of the glass beads. Only when we reduced the amount of microcarriers to $7.5 \mathrm{mg}$ per plate $\left(3 \mathrm{~cm}^{2} /\right.$ plate $)$ in the small scale cultures did we obtain higher yields per $\mathrm{cm}^{2}$.

\section{Cell Growth on Reprocessed Glass Microcarriers}

After removal of cells from the glass microcarriers by trypsinization, the used beads were pooled and stored at room temperature in $1.0 \mathrm{~N} \mathrm{HCl}$. Subsequently the used beads were washed several times with distilled water and dried $\left(110^{\circ} \mathrm{C} /\right.$ dry air $)$ overnight. After reweighing, the used beads were autoclaved at $121^{\circ} \mathrm{C}$ for $15 \mathrm{~min}$. Following this, small-scale cultures were estab- 


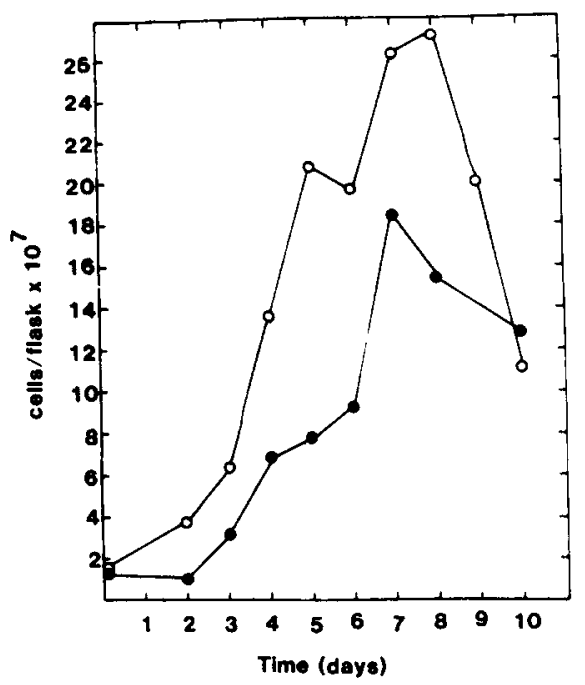

Fig. 4. Growth of KB cells on Cytodex I and on glass microcarriers in $200 \mathrm{~mL}$ suspension cultures. A Techne, model MCS-104, stirring system was used. One-thousand-milliliter culture flasks with $100 \mathrm{~mL}$ of growth medium and either $600 \mathrm{mg}$ of Cytodex I or $2000 \mathrm{mg}$ of the glass microcarriers were inoculated with $1.4 \times 10^{7}$ cells on day zero. Cell-microcarrier interaction was facilitated by intermittant stirring during the first three hours of incubation. Following this, the microcarriers were maintained in suspension by constant stirring (15 rpm for Cytodex I and $20 \mathrm{rpm}$ for the glass microcarriers). Twenty four hours later, each flask received an additional $100 \mathrm{~mL}$ of growth medium. From this time used growth medium was replaced with fresh medium as necessary. At each of the time periods indicated triplicate samples from each flask were harvested and counted. Standard deviations were within $10 \%$ of the mean values. The experiment was run twice and the values shown are the averages of the two experiments combined: (a-a) Cytodex I; (O-O) glass microcarriers.

lished using the reprocessed microcarriers. A comparison of cell yields between unused and reprocessed glass microcarriers is presented in Table II. It can be seen that yields of KB cells and UM-SCC- 2 cells were comparable on the unused and reprocessed glass microcarriers.

\section{Phase Contrast and Scanning Electron Microscopy}

The cells grown on each of the substrata were examined by phase-contrast and scanning electron microscopy. When examined by phase-contrast microscopy, cell growth on the glass microcarriers could be followed by observing the cells around the rim of the microcarrier particles. This is shown with the $\mathrm{KB}$ cells in Figure 5. It can be seen that the microcarrier particles appear to be completely covered by a layer of cells. Although not seen in this figure, multiple cell layers formed around many of the particles. It can also be seen in Figure 5 that the KB cells formed bridges between the microcarriers. Growth patterns of the MRC-5 and UM-SCC-2 cells on the glass microcarriers was similar to that shown here. On the Biosilon spheres patterns of cell growth 
TABLE II

Comparison of Cell Growth on Unused and Reprocessed Glass Microcarriers

\begin{tabular}{llccc}
\hline & & \multicolumn{2}{c}{ Number of cells/mL ( \pm standard deviation, SD) } \\
\cline { 3 - 5 } Microcarrier group & Cell type & $\begin{array}{c}\text { Day } 4 \\
\left(\times 10^{6}\right)\end{array}$ & $\begin{array}{c}\text { Day } 7 \\
\left(\times 10^{6}\right)\end{array}$ & $\begin{array}{c}\text { Day } 8 \\
\left(\times 10^{6}\right)\end{array}$ \\
\hline Unused glass & KB & $1.36 \pm 0.04$ & $0.68 \pm 0.10$ & $0.69 \pm 0.06$ \\
Reprocessed glass & KB & $1.27 \pm 0.20$ & $0.57 \pm 0.02$ & $0.64 \pm 0.11$ \\
Unused glass & UM-SCC-2 & - & $0.65 \pm 0.01$ & $0.90 \pm 0.22$ \\
Reprocessed glass & UM-SCC-2 & - & $0.77 \pm 0.08$ & $0.73 \pm 0.01$ \\
\hline
\end{tabular}

${ }^{a}$ The unused and reprocessed microcarriers were prepared as described in the text. The cultures were established in quadruplicate on day zero and handled in exactly the same manner as the cultures described in Figures 1,2, and 3. Multiple samples from one or two plates were obtained at the times indicated. The values shown are means $( \pm S D)$ of all samples.

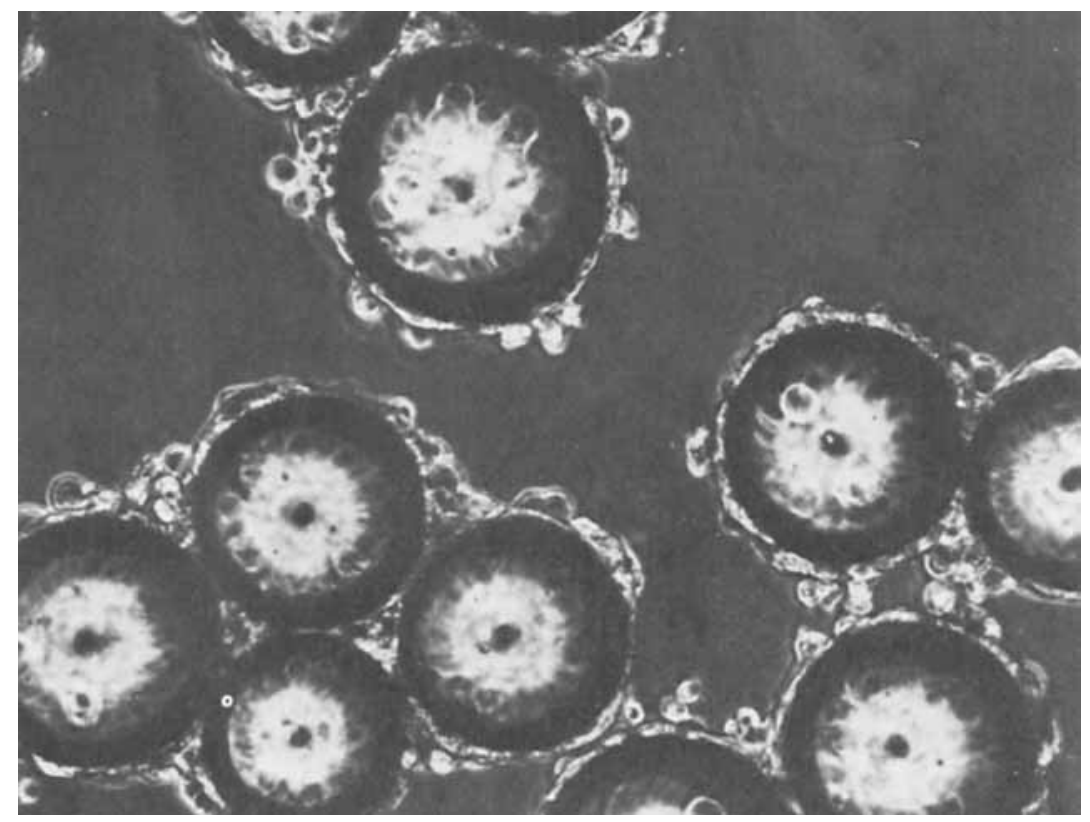

Fig. 5. Phase-contrast photomicrograph of KB cells growing on the glass microcarriers. This photograph shows cells which are clearly visible around the edge of the glass microcarriers. The cells which are in direct contact with the microcarrier surface appear to be flattened. The cells in some areas appear to be growing in more than a single layer and induce the formation of bridges between individual microcarriers (magnification $220 \times$ ). 
were comparable to the patterns observed on the glass microcarriers with all three cell types. In contrast, the three cell types formed only a single layer on the DEAE-dextran microcarriers. Furthermore, with the KB and MRC-5 cells, there was very little clumping of the DEAE-dextran beads although these beads were clumped by the UM-SCC- 2 cells at high density.

In addition to examining the cells by phase-contrasting microscopy, $\mathrm{KB}$ cells grown on the microcarriers were also examined by scanning electron microscopy. Several interesting features of cell growth on the microcarriers were revealed in this way. These features are presented in Figures 6-12. Figures 6 and 7 shown KB cells growing on the glass microcarriers at two different densities. Most of the cells at low density (Fig. 6) are flattened, contain numerous, short microvilli and appear to be attached to the substratum through long, slender filopodia. At higher density, a number of rounded cells are seen. These cells also have numerous microvilli and appear to be attached to the substratum and to other cells through filopodia. These same features are shown at higher magnification in Figures 8 and 9. Although not shown, similar growth patterns were observed with the $\mathrm{KB}$ cells grown on Biosilon microcarriers.

KB cells grown on Cytodex I are shown in Figures 10-12. It can be seen in Figure 10 that the cells grow to confluency on the DEAE-dextran particles although, in contrast to what was observed with the glass and plastic substrata, it appears that only a single layer is formed. The cells grown on this substratum have a very different appearance from the cells grown on the rigid glass or

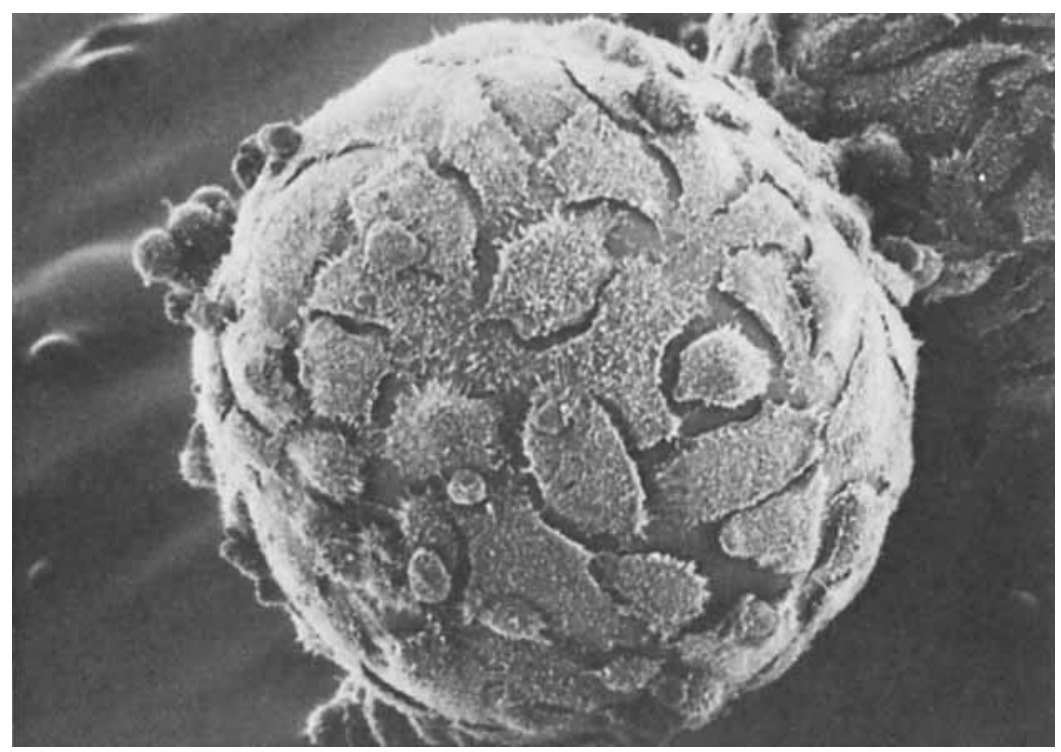

Fig. 6. Scanning electron micrograph of $\mathrm{KB}$ cells growing at low density on the glass microcarriers. A single layer of cells is seen over the glass surface (magnification $520 \times$ ). 


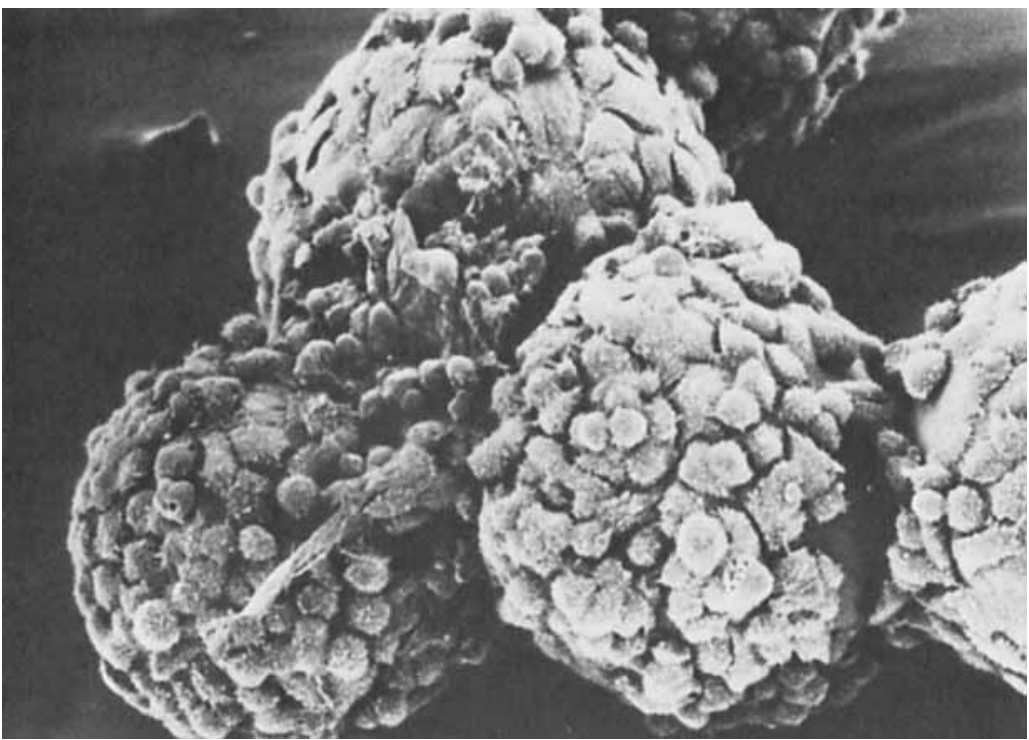

Fig. 7. Scanning electron micrograph of KB cells growing on several glass microcarriers. High density growth with cells bridging the spaces between adjacent microcarriers is seen (magnification $360 \times$ ).

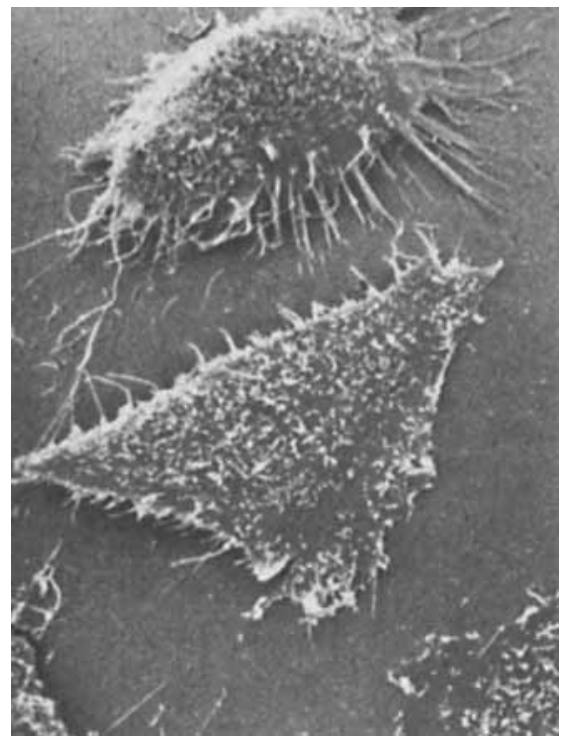

Fig. 8. Scanning electron micrograph of KB cells growing on the glass microcartiers. The cells are at low density and numerous long thin filopodia extending onto the glass surface from the cells can be seen. The microcarrier surface is nearly featureless (magnification $1340 \times$ ). 


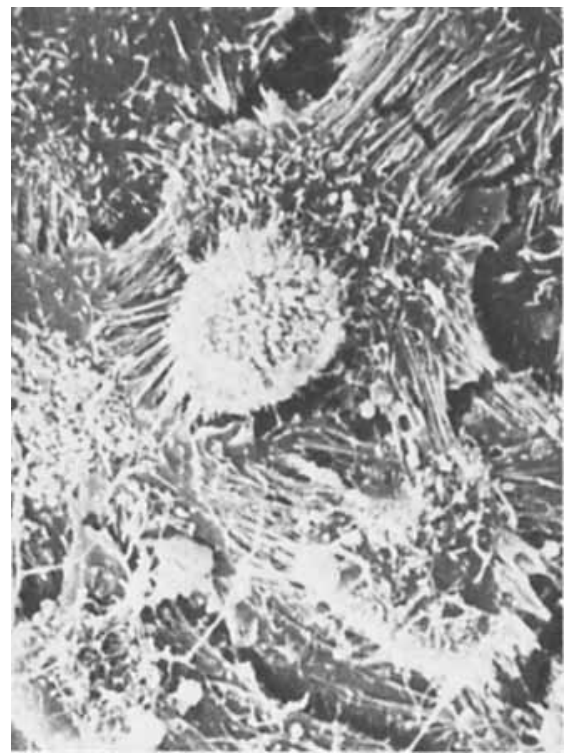

Fig. 9. Scanning electron micrograph of $\mathrm{KB}$ cells growing on the glass microcarriers. High density cell growth with several overlapping layers of cells is seen. The cells are covered with slender filopodia which extend between adjacent cells. Microvilli can also be seen on the cell surfaces (magnification $1770 \times$ ).

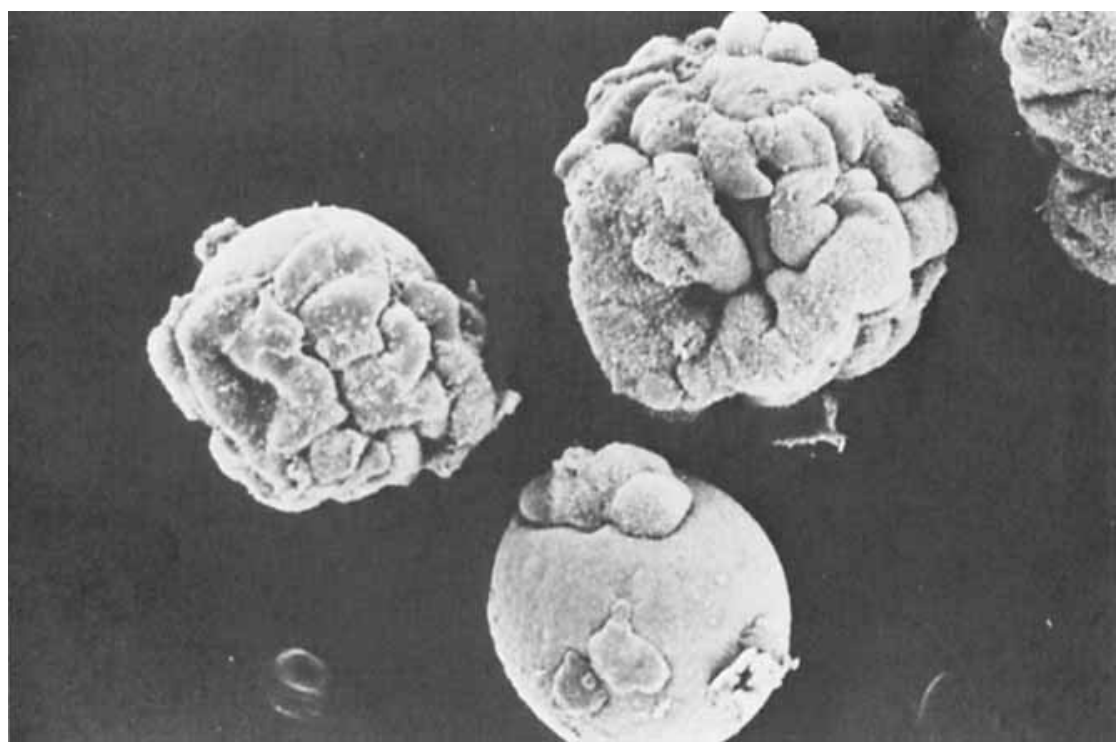

Fig. 10. Scanning electron micrograph of $\mathrm{KB}$ cells growing on Cytodex I microcarriers. The cells appear to form only a single layer over the surface (magnification $480 \times$ ). 


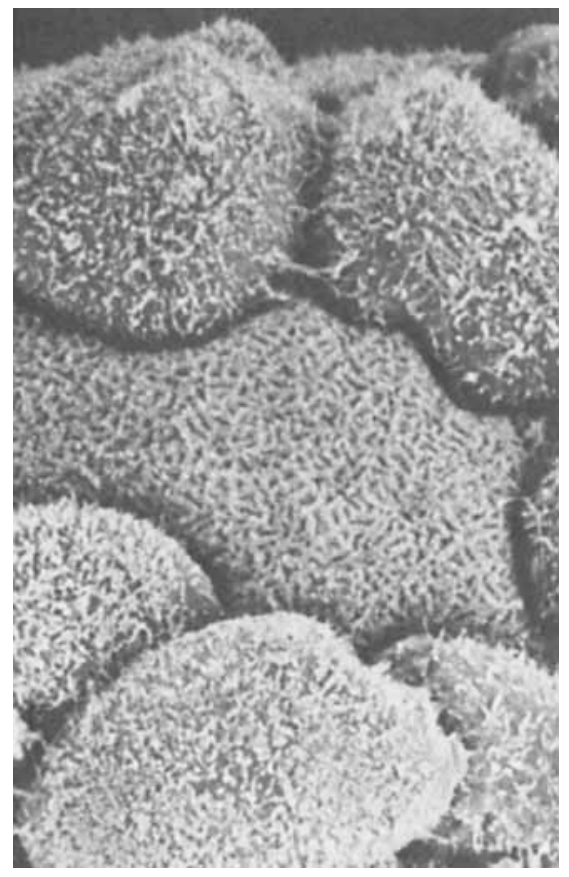

Fig. 11. Scanning electron micrograph of KB cells growing on Cytodex I microcarriers. The textured surface of the microcarrier is exposed in the center of the figure. Microvilli are scattered over the cell surface but filopodia are rare and the entire edge of each cell appears to be in contract with the substratum (magnification $2220 \times$ ).

plastic surfaces. Of particular interest is the fact that the cells do not attach to the substratum through slender filopodia. Rather, the entire edge of each cell appears to be in contact with the substratum. This is clearly seen in Figure 11. On many of the cells, plication of the cell membrane at the point of contact with the substratum is evident (Fig. 12) and in some places it appears as if the cells have actually become imbedded in the textured material. The very different nature of the cell contact with the substratum may account for the differences in susceptibility of the cells to trypsin-mediated release from the substratum. The appearance of cells grown on the Superbead microcarriers (not shown) was very similar to that of the same cells grown on the Cytodex I.

\section{DISCUSSION}

This report describes our initial studies using glass microspheres as a substratum for the growth of anchorage-dependent cells. The microspheres have all the advantages of glass but in addition, they are of sufficiently low particle density $(1.04 \mathrm{~g} / \mathrm{mL})$ to be used in suspension culture with gentle stirring. A number of points can be made regarding cell growth on these glass microcar- 


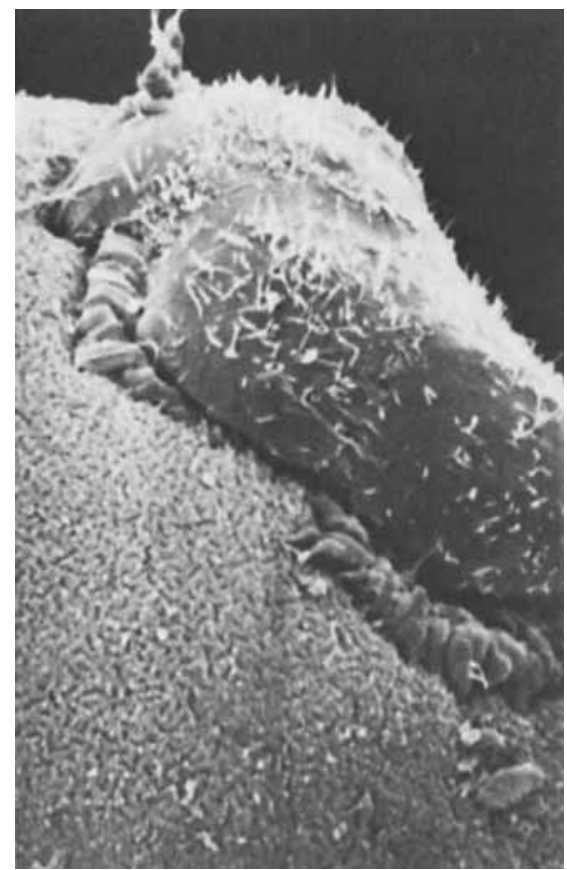

Fig. 12. Scanning electron micrograph of KB cells growing on Cytodex I microcarriers. Microvilli are widely scattered on the cell surface. Irregular cell processes at the interface with the microcarrier surface can be seen. This feature is observed on many of the cells grown on Cytodex I (magnification $2470 \times$ ).

riers. In small-scale cultures, we obtained yields of cells with the glass microcarriers (at 15 and $30 \mathrm{~cm}^{2}$ of surface area per culture) that were comparable to the yields obtained with several commercially available microcarriers used at concentrations recommended by the manufacturers. When we increased the culture size to $200 \mathrm{~mL}$, we also obtained comparable yields with the glass microcarriers to yields with microcarriers of the dextran polymer type.

In addition to the quantitative comparisons, we also examined patterns of cell growth on the experimental glass microcarriers and the commercially available products. Significant differences were observed between the glass microcarriers and the DEAE-dextran microcarriers. These differences could be observed by phase-contrast microscopy. On the DEAE-dextran beads, all three of the cell types used in this study grew as a single layer. Only one of the cell types, the UM-SCC-2 cells, led to clumping of the beads. In contrast all three of the cell types formed extensive bridges between the glass microcarriers and with the KB cells, at least, multiple layers of cells were formed. When viewed by scanning electron microscopy, dramatic differences were observed. On the glass microcarriers, cells attached to the microcarrier particles through long, slender filopodia. In contrast, cell attachment to the DEAE-dextran particles appeared to involve the entire edge of the cell. Furthermore, in many of 
the cells, extensive plication of the membrane at the area of contact with the substratum was observed. The significance of these differences is not known at present. However, it is likely that these differences contribute to the dissimilarity in trypsin-sensitivity between the cells on the two materials. Furthermore, the fact that dramatic morphological differences characterize the cells growing on the two substrata may suggest that more basic biochemical differences between the cells on the same surfaces also exist. Thus, it urges caution in interpreting comparisons made between cells growing on the glass vs cells growing on the DEAE-dextran substrata. Further studies will need to be done in order to show whether yields of viruses of cellular products are significantly different between cells grown on the different materials.

In summary, this report describes the use of a new experimental microcarrier for the growth of anchorage-dependent cell lines. Our studies suggest that this substratum may have significant advantages over products currently available. Cell growth on this substratum is good, and the cells are easily harvested in a viable, healthy state from the substratum. The cells can, therefore, be readily reused. Additionally, since the substratum consists of rigid, glass beads, it may be possible to use them more than once. Finally, it can be expected that the metabolism of the cells growing on the glass microcarriers may be very similar to the metabolism of cells growing in monolayers on glass.

This study was supported by Contract No. 82-958-P1 from KMS Fusion, Inc.

\section{References}

1. A. L. van Wezel, Nature, 2, 64 (1967),

2. D. L. Levine, J. S. Wong, D. I. C. Wang, and W. C. Thilly, Somatic Cell Genet., 3, 149 (1977).

3. Anonymous, Microcarrier Cell Culture: Principles \& Methods (Pharmacia Fine Chemicals, Uppsala, Sweden 1981), p. 27.

4. A. Johansson and V. Nielsen, Dev. Biol. Stand., 46, 125 (1980).

5. M. Hirtenstein, J. Clark, G. Lindgren, and P. Vretblad, Dev. Biol. Stand., 46, 109 (1980).

6. R. E. Spier and J. P. Whiteside, Biotechnol. Bioeng., 18, 649 (1976).

7. R. E. Spier, J. P. Whiteside, and K. Bolt, Biotechnol. Bioeng., 19, 1735 (1977).

8. J. P. Whiteside, B. R. Whiting, and R. E. Spier, Dev. Biol. Stand., 46, 187 (1980).

9. A. L. van Wezel, "Microcarrier cultures of animal cells," in Tissue Culture: Methods and Applications, P. F. Kruse and M. K. Patterson, Eds. (Academic, New York, 1973), p 372.

10. C. J. Krause, T. E. Carey, R. W. Ott, C. Hurbis, K. D. McClatchey, and J. A. Regezi, Arch. Otolaryngol., 107, 703 (1981).

Accepted for Publication November 16, 1982 